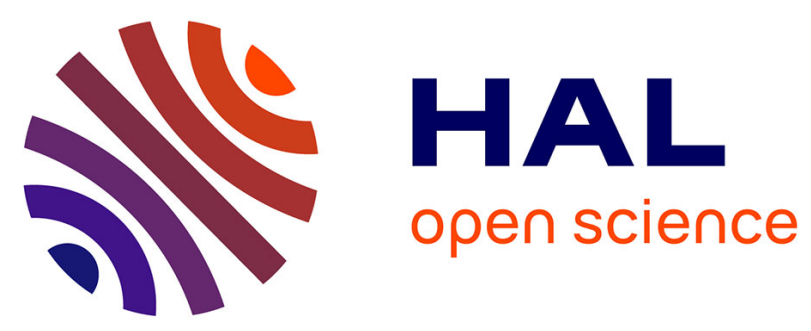

\title{
Porphyrin-based bridged silsesquioxane nanoparticles for targeted two-photon photodynamic therapy of zebrafish xenografted with human tumor
}

\author{
Soraya Dib, Dina Aggad, Chiara Mauriello Jimenez, Ahmed Lakrafi, \\ Guillaume Héry, Christophe Nguyen, Denis Durand, Alain Morère, Khaled El \\ Cheikh, Vincent Sol, et al.
}

\section{To cite this version:}

Soraya Dib, Dina Aggad, Chiara Mauriello Jimenez, Ahmed Lakrafi, Guillaume Héry, et al.. Porphyrin-based bridged silsesquioxane nanoparticles for targeted two-photon photodynamic therapy of zebrafish xenografted with human tumor. Cancer reports, 2019, 2 (5), pp.e1186. $10.1002 / \mathrm{cnr} 2.1186$. hal-02355962

\section{HAL Id: hal-02355962 https://hal.science/hal-02355962}

Submitted on 15 Dec 2020

HAL is a multi-disciplinary open access archive for the deposit and dissemination of scientific research documents, whether they are published or not. The documents may come from teaching and research institutions in France or abroad, or from public or private research centers.
L'archive ouverte pluridisciplinaire HAL, est destinée au dépôt et à la diffusion de documents scientifiques de niveau recherche, publiés ou non, émanant des établissements d'enseignement et de recherche français ou étrangers, des laboratoires publics ou privés. 


\title{
Porphyrin-based bridged silsesquioxane nanoparticles for targeted two-photon photodynamic therapy of zebrafish xenografted with human tumor
}

\author{
Soraya Dib $^{1}$ | Dina Aggad ${ }^{2}$ | Chiara Mauriello Jimenez ${ }^{1}$ | Ahmed Lakrafi ${ }^{2}$ | \\ Guillaume Hery $^{2}$ | Christophe Nguyen ${ }^{2}$ | Denis Durand ${ }^{2}$ | Alain Morère ${ }^{2}$ | \\ Khaled El Cheikh ${ }^{3}$ | Vincent Sol ${ }^{4}$ | Vincent Chaleix ${ }^{4}$ Sofia Dominguez Gil ${ }^{1}$ | \\ Karim Bouchmella ${ }^{1}$ | Laurence Raehm ${ }^{1}$ | Jean-Olivier Durand ${ }^{1}$ | Makhlouf Boufatit ${ }^{5}$ | \\ Xavier Cattoën ${ }^{6}$ | Michel Wong Chi Man ${ }^{1}$ । Nadir Bettache ${ }^{2}$ (D) । Magali Gary-Bobo ${ }^{2}$ (D)
}

${ }^{1}$ CNRS, ENSCM, Institut Charles Gerhardt Montpellier, UMR 5253 Univ Montpellier, Montpellier, France

${ }^{2}$ CNRS, ENSCM, Institut de Biomolécules Max Mousseron, UMR 5247, Univ Montpellier,

Montpellier, France

${ }^{3}$ NanoMedSyn, Faculté de Pharmacie,

Montpellier, France

${ }^{4}$ Laboratoire PEIRENE EA 7500, Univ Limoges, Limoges, France

${ }^{5}$ Laboratoire d'Electrochimie-Corrosion, Métallurgie et Chimie Minérale, USTHB, Faculté de Chimie, Alger, Algeria

${ }^{6}$ Institut NEEL CNRS/UGA UPR2940, Grenoble, France

\section{Correspondence}

Dr Magali Gary-Bobo, Institut de Biomolécules Max Mousseron, UMR 5247, Univ Montpellier, CNRS, ENSCM, Avenue Charles Flahault, 34093 Montpellier cedex 05, France.

Email: magali.gary-bobo@inserm.fr

Funding information

Profas $\mathrm{B}^{+}$programme

\section{Abstract}

Background: Bridged silsesquioxane nanoparticles (BSNs) recently described represent a new class of nanoparticles exhibiting versatile applications and particularly a strong potential for nanomedicine.

Aims: In this work, we describe the synthesis of BSNs from an octasilylated functional porphyrin precursor (PORBSNs) efficiently obtained through a click reaction. These innovative and very small-sized nanoparticles were functionalized with PEG and mannose (PORBSNs-mannose) in order to target breast tumors in vivo. Methods and Results: The structure of these nanoparticles is constituted of porphyrins $J$ aggregates that allow two-photon spatiotemporal excitation of the nanoparticles. The therapeutic potential of such photoactivable nanoparticles was first studied in vitro, in human breast cancer cells in culture and then in vivo on zebrafish embryos bearing human tumors. These animal models were intravenously injected with $5 \mathrm{~nL}$ of a solution containing PORBSNs-mannose. An hour and half after the injection of photoactivable and targeted nanoparticles, the tumor areas were excited for few seconds with a two-photon beam induced focused laser. We observed strong tumor size decrease, with the involvement of apoptosis pathway activation.

Conclusion: We demonstrated the high targeting, imaging, and therapeutic potential of PORBSNs-mannose injected in the blood stream of zebrafish xenografted with human tumors.

\section{KEYWORDS}

bridged silsesquioxane nanoparticles, human tumor targeting, photodynamic therapy, two-photon excitation 


\section{1 | INTRODUCTION}

Nanotechnology represents a major advance in the field of medicine and has started to play an important role in the development of anticancer therapeutics. ${ }^{1,2}$ In the course of the development of more efficient, biocompatible, multifunctional, and stealth nanoparticles for theranostics, we turned to bridged silsesquioxane nanoparticles (BSNs). ${ }^{3}$ Indeed, BSNs were recently described and represent a new class of nanoparticles exhibiting versatile applications in different area of research such as photovoltaics, electrochromism, heterogeneous catalysis, environment, and nanomedicine. ${ }^{4}$ They are obtained through the sol-gel condensation in mild conditions, using organic precursors possessing at least two trialkoxysilane groups without the presence of any silica source. Despite their diverse properties and various relevant applications, several features account for their interest for biomedical use. In fact, the size, morphology, and surface are controllable; the high organic content of BSNs (20-80 wt\%) can be used for theranostic purposes with a strong potential and a good biocompatibility. ${ }^{4}$ We demonstrated in a previous work that these BSNs mainly composed of photosensitizers were very effective for photodynamic therapy (PDT) of cancer cells under two-photon excitation (TPE). ${ }^{5}$

TPE is very attractive for nanomedicine applications $s^{6,7}$ as it allows a deep penetration of the near-infrared beam down to $2 \mathrm{~cm}$ in tissues ${ }^{8}$ and a high spatiotemporal resolution presenting a strong interest for imaging and cancer detection. Importantly, TPE-PDT has demonstrated a high potential for cancer therapy ${ }^{9-26}$ and particularly for small-sized tumor treatment.

Today, the evolution of nanotechnology, involving or not PDT, requires high competitive and accurate methodologies to determine the therapeutic effect and the biocompatibility of the new nanostructured materials for biomedical applications. In particular, the elaboration of integrated models for in vivo studies of nanomaterials becomes a priority for the research in the field of nanomedicine. In 2010, the European directive on the protection of laboratory animals was revised, and it was requested to find alternative methods to the use of sensitive animals such as small mammalians. The embryo is not considered a sensitive animal, and its use is privileged. The zebrafish embryo is a very popular animal model because it is easy to breed, with a fast development, and possesses $80 \%$ of gene homology with humans. ${ }^{27}$ Previous studies have shown that it is a powerful model organism for the study of human biology, being well suited to both developmental and genetic analyses. ${ }^{28}$ Importantly, they can easily develop human tumors due to their lack of immune system in this embryonic state. ${ }^{29}$ Moreover, the embryos that develop outside the mother are transparent, which is a great advantage in our case for tumor imaging. For all these crucial benefits, we propose to use this integrated animal model for investigations on innovative and targeted BSNs for anticancer properties under TPE. Recently, we described new porous porphyrin-based organosilica nanoparticles of a 250-nm average diameter, which were endocytosed in MDA-MB-231 breast cancer cells before being injected in zebrafish embryos. $^{30}$ After 2 days, the tumor developed, and TPE-PDT was successfully performed on the xenografted tumor, showing the proof of concept of TPE-PDT with zebrafish embryos. However, this experiment could be related to an intratumoral injection of nanoparticles, and the size of the nanoparticles which did not allow us to inject in the tail vein was a limit in this work. This is the reason why we decided to synthesize small organic nanoparticles which was very challenging.

Herein, we describe the preparation of small-sized non-porous porphyrin-based BSNs (PORBSNs) from an octasilylated porphyrin precursor, anchored with both stealth polyethyleneglycol (PEG) groups to bring hydrosolubility and mannose groups in order to target breast cancer cells through interactions with lectins overexpressed in MDA-MB-231 breast cancer cells. ${ }^{31}$ The therapeutic potential of these small-sized PORBSNs-mannose is presented in vitro using human breast adenocarcinoma cells (MDA-MB-231) and in vivo through intravenous injection of the nanoparticles in zebrafish xenografted with this cancer cell line. The biological study of TPE-PDT demonstrated their strong efficiency after only a few seconds of irradiation on cell cultures and on human tumors in the zebrafish model.

\section{2 | MATERIAL AND METHODS}

\section{1 | Materials}

Cetyltrimethylammonium bromide (CTAB, 99\%), sodium hydroxide (97\%) DMSO, and $\mathrm{AcOH}$ were purchased from Sigma-Aldrich. EtOH was purchased form Carlo Erba. Aminoundecyltrimethoxysilane and (6-[2-(2-[2-methoxy-ethoxy]-ethoxy)-ethoxy]-hexyl)trimethoxysilane were purchased from SIKEMIA. $p$-[N-(2-Ethoxy-3,4-dioxocyclobut-1enyl)amino]phenyl- $\alpha$-D-mannopyranoside was synthesized as described. ${ }^{32}$

\section{2 | Analytical techniques}

UV-vis absorption spectra were recorded on a Hewlett-Packard 8453 spectrophotometer using correction factors supplied by the manufacturer. $\mathrm{N}_{2}$ adsorption isotherms were measured using a TRISTAR 3000 gas adsorption analyzer instrument, and the specific surface area was determined using the BET method. TEM analysis was performed on a JEOL 1200 EXII instrument. Dynamic light scattering analyses were performed using a Cordouan Technologies DL 135 Particle size analyzer instrument.

\section{3 | Synthesis of porphyrin-based bridged-silsesquioxane nanoparticles (PORBSNs)}

A mixture of CTAB (250 mg, $0.78 \mathrm{mmol})$, distilled water $(120 \mathrm{~mL})$, and $\mathrm{NH}_{4} \mathrm{OH}\left(0.2 \mathrm{M}\right.$ aqueous solution, $1.2 \mathrm{~mL}$ ) was stirred at $80^{\circ} \mathrm{C}$ for 2 hours at $750 \mathrm{rpm}$ in a $250-\mathrm{mL}$ three-neck round bottom flask. Then, the octasilylated porphyrin ${ }^{30}(100 \mathrm{mg}, 0.0327 \mathrm{mmol}$, in $2 \mathrm{~mL}$ of absolute ethanol) was added, and the mixture was stirred for 
30 hours at $80^{\circ} \mathrm{C}$. Afterwards, the solution was cooled to room temperature while stirring and stored in the fridge.

\section{4 | Synthesis of mannose-functionalized porphyrin-based bridged-silsesquioxane nanoparticles (PORBSNs-mannose)}

Twenty milligrams of aminoundecyltrimethoxysilane $(0.09 \mathrm{mmol})$ was dissolved in $10 \mathrm{~mL}$ of anhydrous $\mathrm{EtOH} ; 349 \mathrm{mg}$ of $p$-[N-(2-ethoxy3,4-dioxocyclobut-1-enyl)amino]phenyl- $\alpha$-D-mannopyranoside (squarate mannose) $(0.88 \mathrm{mmol} ; 10$ eq.) was added to the solution. The mixture was stirred at $50^{\circ} \mathrm{C}$ overnight and then cooled to room temperature. The crude mixture was centrifuged (15 000 rpm; $5 \mathrm{~min}$ ). The supernatant was removed, and the pellet was resuspended in $\mathrm{EtOH}$. This operation was renewed once. After removal of the supernatant, the product was recovered as a pale yellow paste. This paste was stored without further drying.

Twelve milligrams of this paste was dissolved in $1.3 \mathrm{~mL}$ of DMSO, and $100 \mathrm{mg}$ of (6-[2-(2-[2-methoxy-ethoxy]-ethoxy)-ethoxy]-hexyl) trimethoxysilane was added. This solution was added to $8 \mathrm{~mL}$ of the solution of PORBSNs and the mixture stirred at $700 \mathrm{rpm}$ and $50^{\circ} \mathrm{C}$ for one night. After reaction, excess reagents and $C T A B$ were removed by dialysis (cutoff $12 \mathrm{kDa}$ ) in a mixture of $\mathrm{EtOH} / \mathrm{H}_{2} \mathrm{O} / \mathrm{AcOH}$ : $1 / 1 / 0.07$ for 24 hours. The operation was repeated twice. The suspension was then dialyzed in $\mathrm{EtOH}$ for $3 \times 24$ hours and stored at room temperature in $\mathrm{EtOH}$.

\section{5 | Cell culture}

Human breast adenocarcinoma cells MDA-MB-231expressing (or not) green fluorescent protein (GFP) (purchased from ATCC) were cultured in DMEM Media-GlutaMAX-I (containing $4.5 \mathrm{~g} . \mathrm{L}^{-1}$ of D-glucose) supplemented with $10 \%$ fetal bovine serum and $50 \mu \mathrm{g} \mathrm{m}^{-1}$ gentamycin and allowed to grow in humidified atmosphere at $37^{\circ} \mathrm{C}$ under $5 \% \mathrm{CO}_{2}$.

\section{6 | Cytotoxicity measurement}

For in vitro cytotoxicity analysis, MDA-MB-231 cells were seeded into a 96-well plate, 1000 cells per well in $200 \mu \mathrm{L}$ of culture medium, and allowed to grow for 24 hours. Then, cells were treated with increasing concentrations of PORBSNs-mannose, and after 3 days, a MTT assay was performed as previously described. ${ }^{25}$

\section{7 | OPE or TPE-PDT experiments}

For in vitro OPE-PDT, MDA-MB-231 cells were seeded into a 384 multiwell plate (in plastic), 500 cells per well in $50 \mu \mathrm{L}$ of culture medium, and allowed to grow for 24 hours. Then, cells were treated with $80 \mu \mathrm{g} \mathrm{mL} \mathrm{m}^{-1}$ PORBSNs mannose, and 24 hours after, cells were submitted (or not) to laser irradiation (442-440 nm) with the mercury lamp of a fluorescence standard microscope. After 2 days, MTT assay was performed to measure the level of living cells.
For in vitro TPE-PDT, MDA-MB-231 cells were seeded into a 384 multiwell glass-bottomed plate (thickness $0.17 \mathrm{~mm}$ ), with a black polystyrene frame, 500 cells per well in $50 \mu \mathrm{L}$ of culture medium, and allowed to grow for 24 hours. Then, cells were treated with $80 \mu \mathrm{gL}^{-1}$ PORBSNs-mannose, and 24 hours after, cells were submitted (or not) to laser irradiation, with the Carl Zeiss Microscope (laser power input $3 \mathrm{~W}$ ). Half of the well was irradiated at $800 \mathrm{~nm}$ by three scans of 1.57-seconds duration in four different areas of the well. The laser beam was focused by a microscope objective lens (Carl Zeiss 10×/0.3 EC Plan-Neofluar). The scan size does not allow irradiating more areas without overlapping. After 2 days, the MTT assay was performed as previously described ${ }^{25}$ and was corrected according to the following formula: Abs control $-2 \times$ (Abs control $\times$ Abs PORBSNs-mannose).

\section{8 | ROS imaging under one or two-photon excitation}

The detection of intracellular reactive oxygen production (ROS) was realized using DCF-DA Cellular ROS Detection Assay Kit (abcam). For ROS measurement under monophotonic excitation, MDA-MB231 cells were seeded in a 12-well plate and treated with PORBSNs-mannose at $80 \mu \mathrm{g} \mathrm{mL} \mathrm{L}^{-1}$. After 24 hours, cells were rinsed and incubated 45 minutes at $37^{\circ} \mathrm{C}$ with 2,7 -dichlorofluorescein diacetate (DCFDA) at $20 \mu \mathrm{M}$. Then, cells were rinsed and submitted or not to an irradiation with a mercury lamp, during 10 minutes $(\lambda=420-440 \mathrm{~nm})$. Green luminescence translates the generation of ROS detected at $535 \mathrm{~nm}$.

For ROS measurement under biphotonic excitation, cells were seeded in bottom glass dishes (World Precision Instrument, Stevenage, UK) at a density of $10^{6}$ cells $\cdot \mathrm{cm}^{-2}$ and submitted to the same protocol with an excitation with a LSM 780 LIVE confocal microscope (Carl Zeiss, Le Pecq, France), at $800 \mathrm{~nm}(3 \times 1.57$ seconds) followed by washing and imaging at $535 \mathrm{~nm}$.

\section{9 | Two-photon fluorescence imaging}

The day prior to the experiment, MDA-MB-231 cells expressing GFP were seeded onto bottom glass dishes (World Precision Instrument, Stevenage, UK) at density of $10^{6}$ cells $\mathrm{cm}^{-2}$. Adherent cells were then washed once and incubated in a 1-mL medium containing or not PORBSNs-mannose at a concentration of $80 \mu \mathrm{g} \mathrm{mL} \mathrm{m}^{-1}$ for 24 hours. Fifteen minutes before the end of incubation, cells were loaded with Cell Mask orange (Invitrogen, Cergy Pontoise, France) for membrane staining at a final concentration of $1 \mu \mathrm{g} \mathrm{mL} \mathrm{m}^{-1}$. Before visualization, cells were washed gently with cell media. Cells were then scanned with a LSM 780 LIVE confocal microscope (Carl Zeiss, Le Pecq, France), at $800 \mathrm{~nm}$ for PORBSNs-mannose, $488 \mathrm{~nm}$ for GFP and $561 \mathrm{~nm}$ for cell membranes. All images were performed with a high magnification (63×/1.4 OIL DIC Plan-Apo). 


\subsection{0 | Cell preparation for injection}

The day of the experiment, the cells were washed twice, trypsined, and then stained with $2 \mu \mathrm{g} \cdot \mathrm{mL}^{-1}$ of Dil Stain (1,1'-dioctadecyl3,3,3',3'-tetramethylindocarbocyanine perchlorate ("Dil"; $\left.\operatorname{DilC}_{18}(3)\right)$ ) (Invitrogen), 15 minutes at $37^{\circ} \mathrm{C}$.

In parallel, the cells were deposited on a counting chamber (MARIENFELD SUPERIOR), to determine the number of cells per volume unit of liquid. The stained cells were diluted to final concentration of $10^{8}$ cells $\cdot \mathrm{mL}^{-1}$ in Dulbecco's phosphate-buffered saline (DPBS) supplemented with $10 \%$ fetal bovine serum. The cells are maintained in ice until injection, which must be done within 3 hours after the preparation of the cells.

\subsection{1 | Zebrafish used model and cancer cell injection}

Zebrafish experiments were done according to the guidelines of the European Community Council directive 2010/63/EU and to the accreditation number of the zebrafish facility A34-172-37 of the University of Montpellier. Casper line, zebrafish pigmentation mutants, were purchased from the Zebrafish International Resource Center (ZIRC) as embryos and raised to adulthood in Roussel lab's facilities. Only fish directly from ZIRC or their F1 offspring were used as egg producers to avoid inbreeding effects. Embryos were obtained from pairs of adult fish by natural spawning and raised at $28.5^{\circ} \mathrm{C}$ in tank water. Embryos and larvae were staged according to Kimmel et al. ${ }^{33}$

Zebrafish larvae were manually dechorionated and anesthetized. One hundred cells per nanoliter were injected into the perivitelline space on embryos/early larvae aged 24 to 30 hours postfertilization (hpf); between 5 and $10 \mathrm{~nL}$ was injected each time. The injected or not larvae were allowed to develop at $32^{\circ} \mathrm{C}$. It was observed at 24 hours post-injection (hpi) under an Olympus MVX10 epifluorescence microscope. Only the larvae with homogeneous and comparable xenografts were kept.

PORBSNs-mannose are diluted to $4 \mathrm{mg} \mathrm{mL}^{-1}$ in water containing $1 \%$ phenol red and then intravenously injected $(5 \mathrm{~nL})$ on xenografted zebrafish larvae of 4 days postfertilization.

For each condition, the injected (or not) embryos were divided into two sets: one that will be irradiated and the other not. In the order to follow and compare the xenografts evolution, the irradiated or not larvae were allowed to develop at $32^{\circ} \mathrm{C}$ until the sixth day.

\subsection{2 | Two-photon excited photodynamic therapy of zebrafish}

For two-photon excited irradiation, zebrafish larvae were placed into a multiwell glass bottom with the Carl Zeiss Microscope (laser power input $3 \mathrm{~W}$ ). The laser beam was focused by a microscope objective lens (Carl Zeiss 10×/0.3 EC Plan-Neofluar). The tumor area of zebrafish larvae was irradiated at $800 \mathrm{~nm}$ by three scans of 1.57-second duration.

\subsection{3 | Zebrafish fluorescence imaging}

The injected or not larvae were imaged before and 2 days after two-photon irradiation. Each larvae was placed into a multiwell glass bottom (thickness $0.17 \mathrm{~mm}$ ) and scanned with a LSM 780 LIVE confocal microscope (Carl Zeiss, Le Pecq, France), at 561 nm. All images were performed by a confocal microscope objective 20x (PlanApochromat 20×/0.8 M27). The quantification of fluorescence intensities and tumor volumes in zebrafish embryos were performed by ImageJ software after 3D reconstruction of Z-stacks. For reconstitution of tumor treated with PORBSNs-mannose and laser, 47 Z-stacks were performed with a slice thickness of $2.72 \mu \mathrm{m}$ each one. For reconstitution of tumor treated with PORBSNs-mannose alone, 274 Z-stacks were necessary with a slice thickness of $3.86 \mu \mathrm{m}$ each one. For finish, reconstitution of tumor submitted to laser only, 242 Z-stacks were performed with a slice thickness of $4.4 \mu \mathrm{m}$ each one.

\subsection{Immunofluorescence staining in toto zebrafish}

The embryos were fixed at 6 days postfertilization in paraformaldehyde (PFA) $4 \%$ in PBS + $0.5 \%$ triton at room temperature (RT) for 3 hours, under hood, and then washed with PBS at least 3 times. Fixed embryos were permeabilized using Triton \% in PBS for 2 hours, at RT. In order to saturate the potential unspecific sites antibodies, the embryos were then blocked with blocking solution, containing: PBS $1 \mathrm{X}+\mathrm{BSA} 1 \mathrm{X}+\mathrm{DMSO} 1 \mathrm{X}+10 \%$ Donkey serum (Sigma-Aldrich D9663) for 1 day at $4^{\circ} \mathrm{C}$.

Primary cleaved caspase-3 (Asp175) antibodies (Cell Signaling Technology) were used for specific labeling of the apoptosis signal. The recommended antibody dilution is 1:400 in a blocking solution containing $2 \%$ of Donkey serum. The larvae were incubated over the weekend at $4^{\circ} \mathrm{C}$ and then washed during the day in PBS. At the end of the day, the larvae were labeled with the secondary antibody conjugated to Cy5 at the dilution of 1:500 and incubated overnight at $4^{\circ} \mathrm{C}$. Then, the larvae were washed whole day in PBS and stained with Hoechst dye at the last wash at the concentration of $7 \mu \mathrm{g} \mathrm{mL}^{-1}$ during 40 minutes and finally washed, again, at least three times with PBS. The immunostained larvae were mounted flat onto transparent slides with a coverslip (using Dako fluorescent mounting medium).

\subsection{5 | Zebrafish 3D imaging}

Confocal fluorescence microscopy was performed using a Leica DM2500CSQ upright microscope with a Leica TCS SPE confocal scan head, differential interference contrast (DIC) optics, and a SuperZGalvo SPE z-step controller. The acquisition of threedimension stacks was performed with $63 \times$ Leica Apo oil 1.15 NA. Final image analysis and reconstitution were performed using Imaris X64 8.02 software. 


\section{3 | RESULTS}

\section{1 | PORBSNs and PORBSNs-mannose: Synthesis and characterization}

The synthesis of PORBSNs was performed from a porphyrin precursor $^{30}$ possessing eight triethoxysilyl groups (Scheme 1). The solgel reaction was carried out in diluted conditions using cetyltrimethylammonium bromide (CTAB) as a template and $\mathrm{NH}_{3}$ as a catalyst. The condensation was performed for 30 hours at $80^{\circ} \mathrm{C}$ yielding a colloidal suspension of small-sized PORBSNs. After cooling, the suspension was stable and was stored in the fridge without purification in order to keep the colloidal stability.

Nitrogen sorption performed on the dried nanoparticles revealed a low specific surface area $\left(20 \mathrm{~m}^{2} \mathrm{~g}^{-1}\right)$ indicating that the nanoparticles were not porous. This was confirmed by transmission electron microscopy (TEM) (Figure 1A) that depicts mainly nanoparticles of small size (between 20 and $30 \mathrm{~nm}$ ), while some bigger nanoparticles $(100 \mathrm{~nm})$ were also observed. These nanoparticles were much smaller than our previously reported BS nanoparticles obtained from a tetrasilylated porphyrin precursor, ${ }^{3}$ which showed a size distribution centered at $106 \mathrm{~nm}$. Dynamic light scattering (DLS) of the suspension of PORBSNs (Figure 1B) suggests that small-sized nanoparticles prevailed in a solution with a distribution centered at $20 \mathrm{~nm}$. The biggest nanoparticles $(50-100 \mathrm{~nm})$ represented a minor contribution. PORBSNs were then functionalized with PEG and mannose following our recently published method for small-sized mesoporous silica nanoparticles (Scheme 1). ${ }^{32}$ Well-dispersed small-sized nanoparticles were obtained as suggested by TEM (Figure 1C) and DLS (Figure 1D), with a decrease of the mean hydrodynamic diameter to $7 \mathrm{~nm}$ with a narrow size distribution. This can be explained by the elimination of excess CTAB during the procedure of grafting, due to extensive dialysis with $\mathrm{AcOH} / \mathrm{EtOH}$ which led to disaggregation of the nanoparticles. PORBSNs-mannose were stored in $\mathrm{EtOH}$ at $0^{\circ} \mathrm{C}$, and the suspension was stable at concentrations as high as $14 \mathrm{mg} \mathrm{mL}^{-1}$.

UV-vis spectra of the porphyrin precursor, PORBSNs, and PORBSNs-mannose are presented in Figure 2.

The metallated porphyrin showed the characteristic Soret band at $425 \mathrm{~nm}$ and the two Q bands at 558 and $600 \mathrm{~nm}$. PORBSNs showed an enlarged Soret band at $440 \mathrm{~nm}$ and the two Q bands at 564 and $604 \mathrm{~nm}$. Compared with the precursor, the bands were redshifted in PORBSNs in agreement with the formation of $\mathrm{J}$ aggregates of porphyrins, which endows the nanoparticles with two-photon sensitivity. ${ }^{30}$ PORBSNs-mannose showed the characteristic bands of the $J$ porphyrin aggregates and of the phenyl-squarate moiety at $320 \mathrm{~nm}$, confirming a successful functionalization of BSNs with mannose.

\section{2 | In vitro biological study}

The biocompatibility of PORBSNs-mannose was first investigated on human cancer cells in culture. The absence of toxicity of PORBSNs-mannose in the dark was verified on human breast adenocarcinoma cells (MDA-MB-231) incubated 72 hours with increasing concentrations of PORBSNs-mannose. At the end of the experiment, the living cells were quantified by a colorimetric assay (MTT). The experiment is described in Figure 3 and showed no significant cell death in a range of nanoparticles from 10 to $200 \mu \mathrm{gL}^{-1}$.

The one-photon excited PDT (OPE-PDT) efficiency of PORBSNsmannose was first investigated on MDA-MB-231 breast cancer cells. We studied OPE-PDT and the reactive oxygen species (ROS) production of the nanoparticles with a monophotonic excitation (420-440 nm for 10 minutes, using the mercury lamp of a standard fluorescence microscope). MDA-MB-231 cells incubated for 24 hours with $80 \mu \mathrm{gL} \mathrm{m}^{-1}$ PORBSNs-mannose underwent a significant cell death of $44 \%$ after 10 minutes of irradiation (Figure 4A). The PDT effect is due to the production of ROS which leads to the destabilization of cell and organelle membranes, DNA alteration, and finally cell death. We verified that the phototoxicity observed after nanoparticles treatment and irradiation was due to ROS production. For this, cells were treated with PORBSNs-mannose in the same conditions as those used for PDT, but before irradiation, 20- $\mu$ M 2,7-dichlorofluorescein diacetate (DCFDA) were added in a culture medium (Figure 4B). The green luminescence detected at $535 \mathrm{~nm}$ was characteristic of the generation of ROS.

We then investigated two-photon excited PDT (TPE-PDT) with PORBSNs-mannose. As shown in Figure 5A, PORBSNs-mannose led to $50 \%$ cancer cell death after a few seconds of excitation

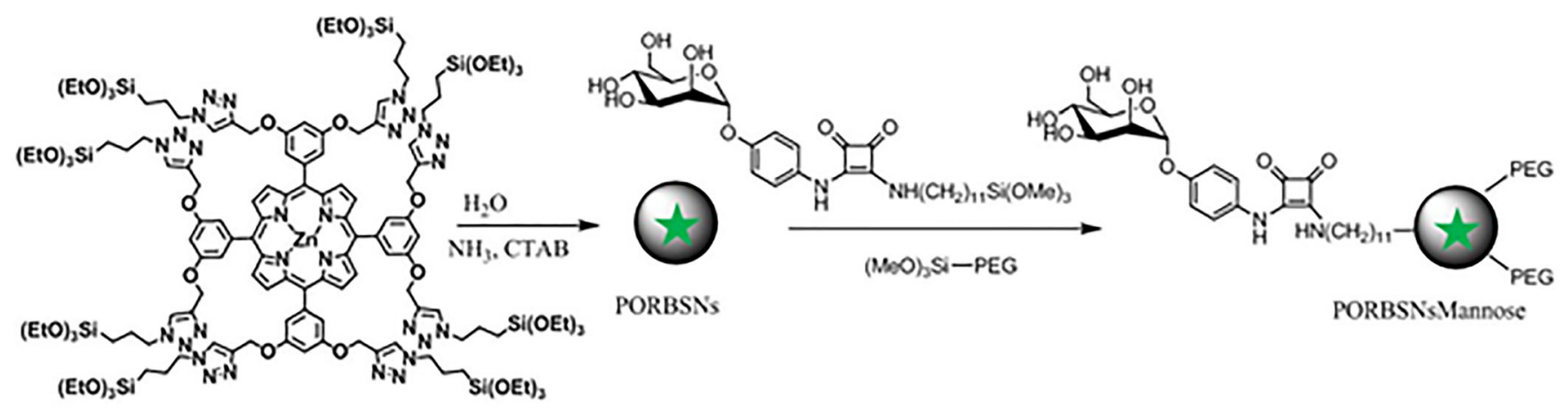

SCHEME 1 Synthesis of PORBSNs and grafting of both PEG and mannose moieties (PORBSNs-mannose). 


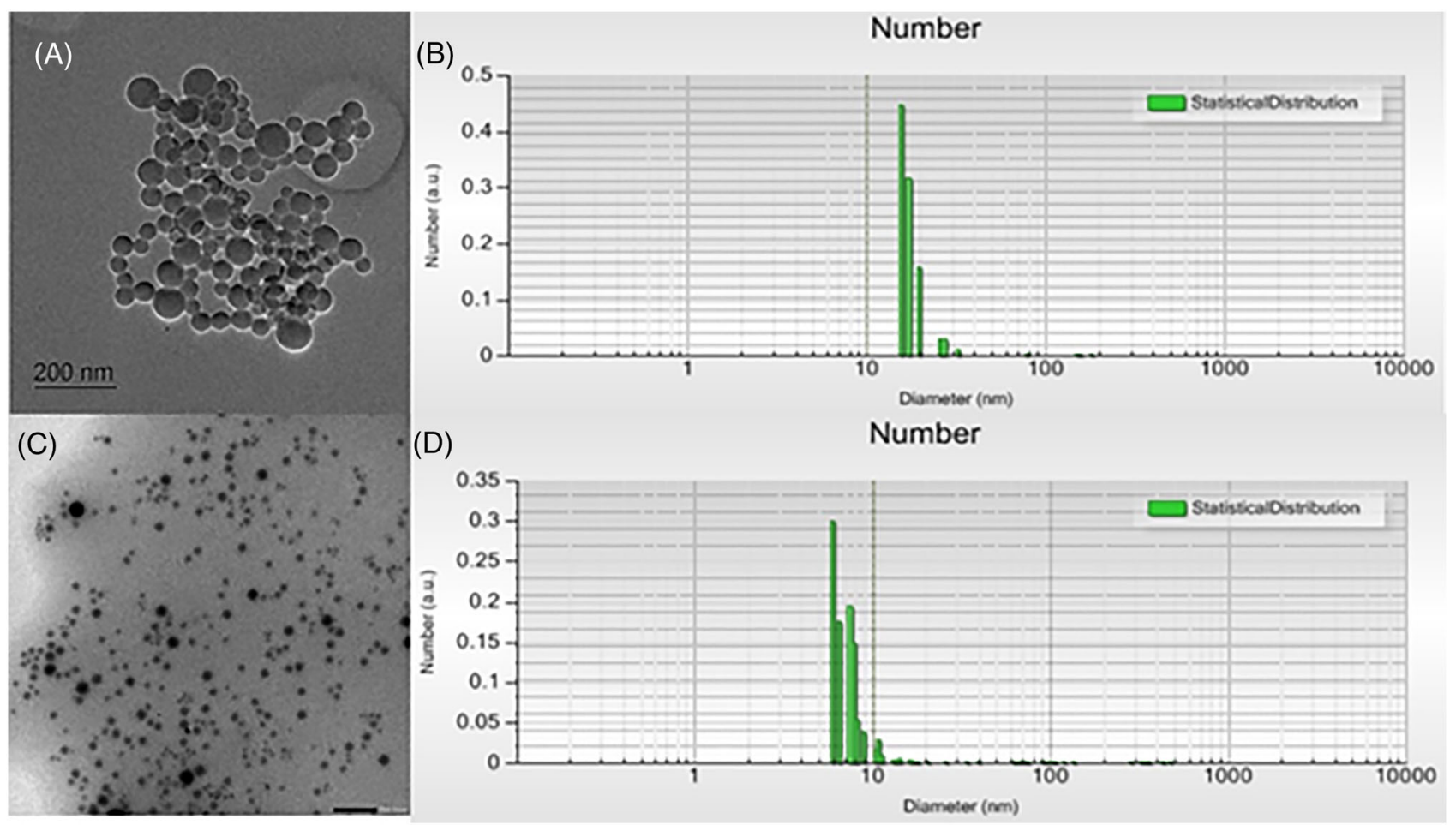

FIGURE 1 A, TEM of PORBSNs. B, DLS of PORBSNs in EtOH. C, TEM of PORBSNs-mannose (scale bar 200 nm). D, DLS of PORBSNs-mannose in $\mathrm{EtOH}$

$(3 \times 1.57$ seconds at $800 \mathrm{~nm})$ with a femtosecond pulsed laser. This effect was due to the production of ROS in the cells treated with PORBSNs-mannose and irradiated with TPE, as demonstrated in Figure $5 \mathrm{~B}$.

The internalization of the nanoparticles in cancer cells was then assessed after 24 hours of incubation at $80 \mu \mathrm{g} \mathrm{mL} \mathrm{L}^{-1}$ with a two-photon Carl Zeiss confocal microscope at low power (3\%, input power $3 \mathrm{~W}$, excitation at $800 \mathrm{~nm}$ ) (Figure 6). Bright fluorescent dots were observed with PORBSNs-mannose and were localized in the cells, thus demonstrating nanoparticle uptake.

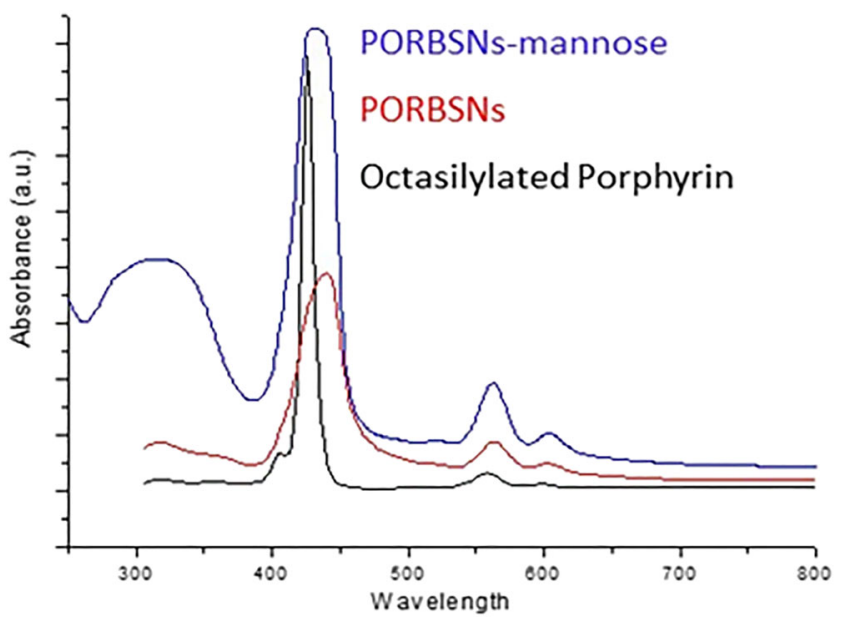

FIGURE 2 UV-vis spectra of octasilylated porphyrin precursor, PORBSNs, and PORBSNs-mannose in EtOH
To investigate in vivo TPE-PDT, we used zebrafish larvae as an integrated model for human tumor. The efficiency of PORBSNsmannose with this model was studied. First, MDA-MB-231 human breast adenocarcinoma cells (stained with red Dil stain) were implanted in the perivitelline space of embryos 24 to $30 \mathrm{hpf}$. The successfully injected embryos were sorted using the red luminescence of MDA-MB-231. The homogeneous xenografted zebrafish embryos were then kept for 2 days until the development of the tumors. Four days postfertilization (dpf), the embryos were intravenously injected or not with PORBSNs-mannose and then submitted or not to TPE irradiation 1.5 hours after the injection of the nanoparticles. Finally, the zebrafish embryos were bred 2 days longer to evaluate the evolution of the xenografts.

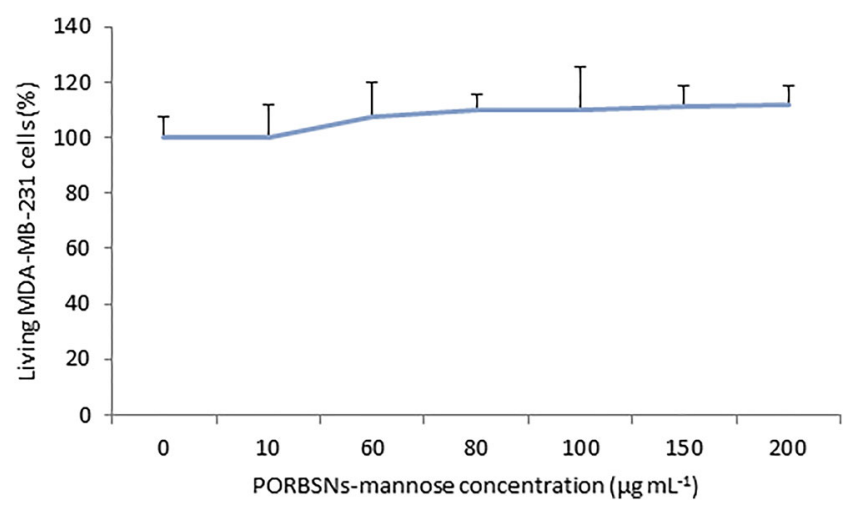

FIGURE 3 Cytotoxic study of PORBSNs-mannose on MDA-MB-231 cells treated with increasing concentrations of nanoparticles during $72 \mathrm{~h}$. Data are mean \pm standard deviation of three experiments 
(A)

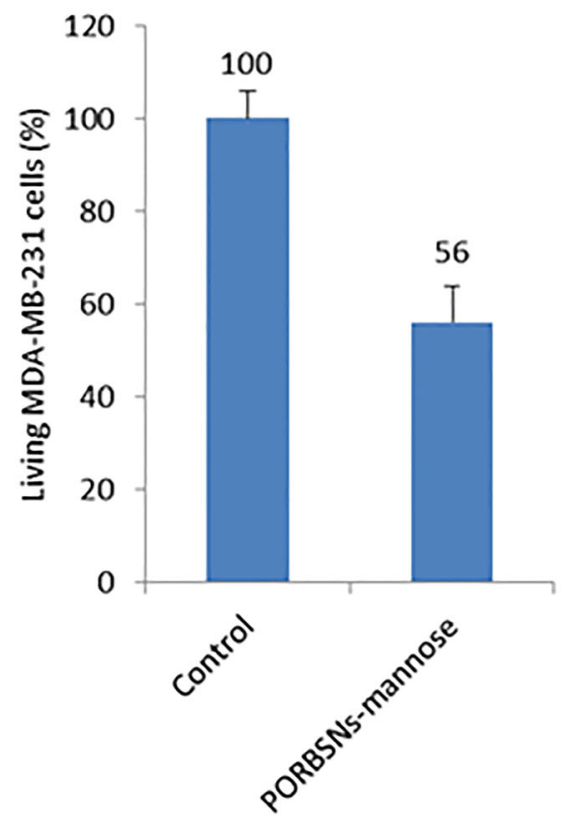

(B)

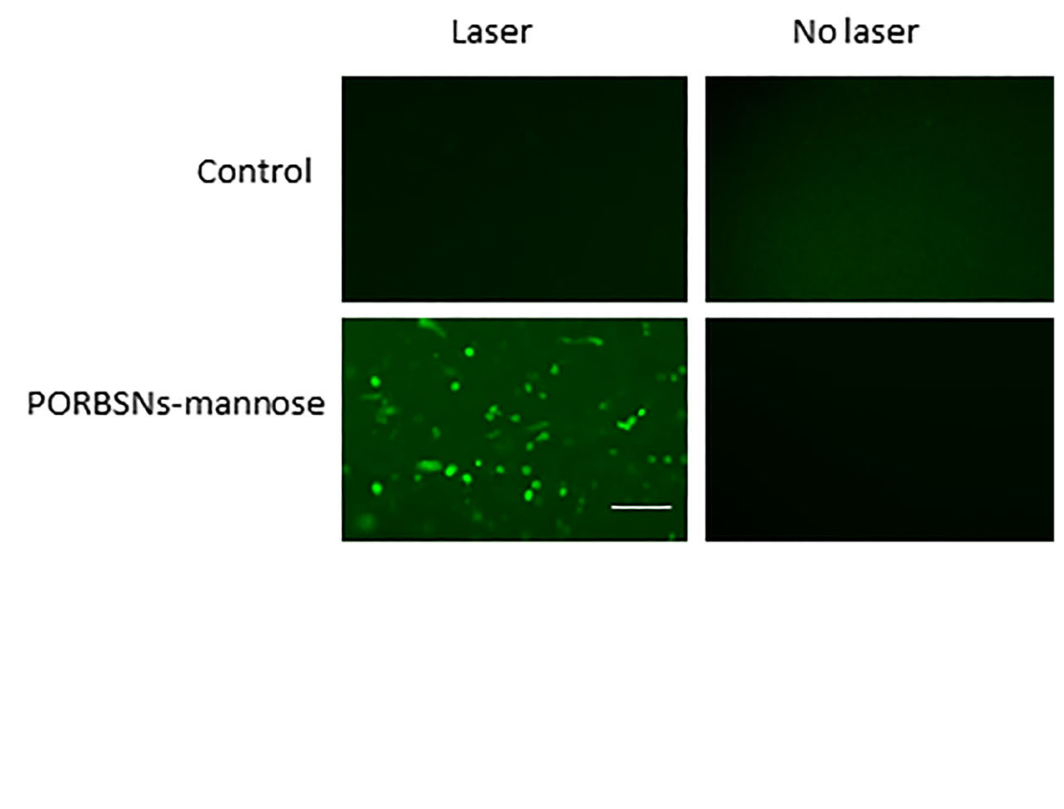

FIGURE 4 Phototoxicity study of PORBSNs-mannose on MDA-MB-231 cells treated with $80 \mu \mathrm{mL}{ }^{-1}$ of nanoparticles. A, PDT efficiency of PORBSNs-mannose after cell irradiation at 420 to $440 \mathrm{~nm}$ for $10 \mathrm{~min}$. Cell death quantification was realized by MTT assay $48 \mathrm{~h}$ after irradiation. Data are mean \pm standard deviation of three experiments. ${ }^{*} P \leq 0.05$ statistically different from control (Student $t$ test). B, ROS production by MDA-MB-231 cells after PORBSNs-mannose incubation. Cells are incubated with DCF-DA and irradiated (420-440 nm, 10 min). Green luminescence translates ROS production by cancer cells (scale bar $50 \mu \mathrm{m}$ )

FIGURE 5 In vitro TPE-PDT experiment and ROS production of PORBSNs-mannose incubated for $24 \mathrm{~h}$ at $80 \mu \mathrm{g} \mathrm{mL}{ }^{-1}$ with MDAMB-231. A, Cell survival measurements are achieved by MTS assay $48 \mathrm{~h}$ after irradiation (at $800 \mathrm{~nm}$ with a pulsed laser for $3 \times 1.57 \mathrm{~s}$ ). Data are mean values \pm standard deviation from three independent experiments. ${ }^{*} P \leq 0.05$ statistically different between laser OFF and laser ON (Student $t$ test). B, Reactive oxygen species (ROS) were detected on MDA-MB-231 cancer cells incubated or not with PORBSNs-mannose $\left(80 \mu \mathrm{g} \mathrm{mL}^{-1}\right.$ for $24 \mathrm{~h}$ ) and added with DCF-DA 45 min before irradiation (at $800 \mathrm{~nm}$ with a pulsed laser for $3 \times 1.57$ s). Generated ROS were monitored by the green fluorescence of 2,7dichlorofluorescein at $535 \mathrm{~nm}$ (scale bar $50 \mu \mathrm{m})$
(A)
(B)

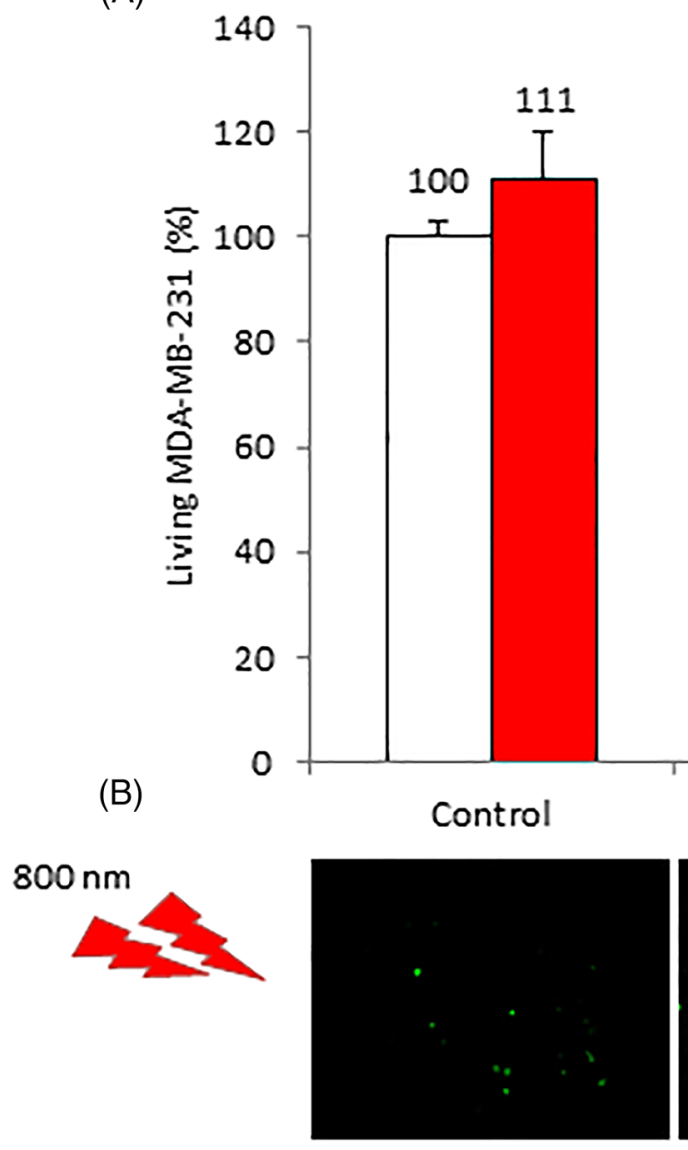

$\square$ Laser OFF

$\square$ Laser ON
PORBSNs-mannose

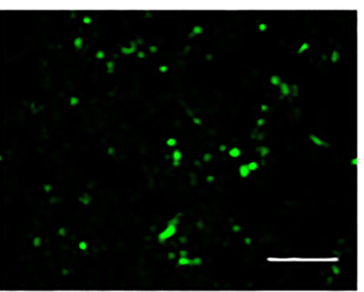




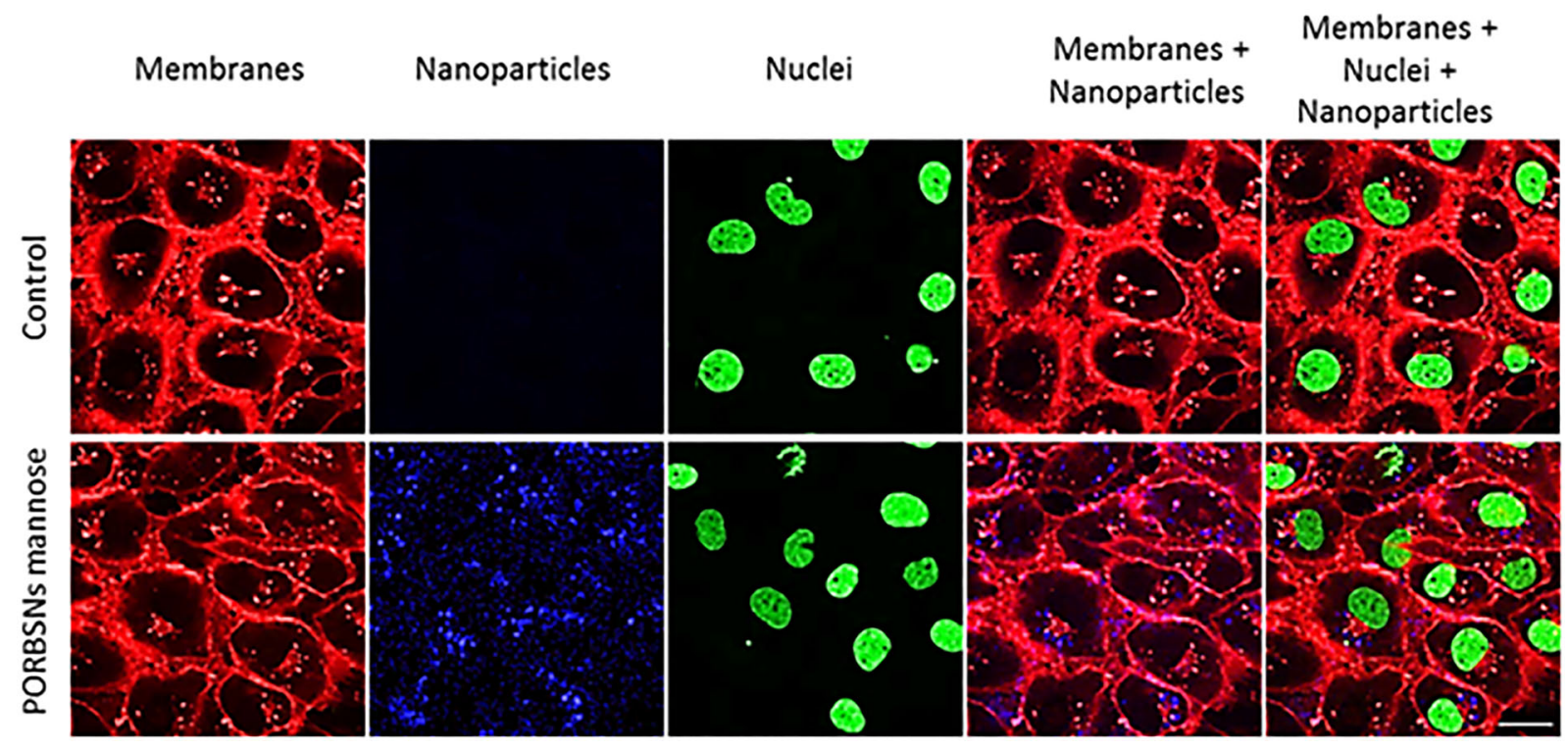

FIGURE 6 In vitro two-photon fluorescence imaging of PORBSNs-mannose (blue) incubated for $24 \mathrm{~h}$ at $80 \mu \mathrm{g} \mathrm{mL} \mathrm{L}^{-1}$. MDA-MB-231 cells express GFP in the nuclei (green). Cell membranes are stained by cell mask (red). All images were performed with $63 \times$ Leica Apo oil (scale bar $10 \mu \mathrm{m})$

As shown in Figure 7A, a clear evolution of the xenografts was observed 6 dpf with live larvae injected with MDA-MB-231 cells and PORBSNs-mannose without TPE. Then, TPE was performed on larvae injected with MDA-MB-231 cells without previous PORBSNsmannose treatment, in order to demonstrate that the irradiation at $800 \mathrm{~nm}$ did not affect the zebrafish embryo survival or tumor development. In contrast, the intravenous injection of PORBSNs-mannose followed by the two-photon irradiation significantly reduced the xenografts size (Figure 7A). This experiment was repeated and finally done four times. As reported in Figure 7B, in all cases, the xenografted animals showed an increase in tumor size while when zebrafish embryos bearing tumor were also injected with PORBSNs-mannose and irradiated the tumor area during $3 \times 1.57$ seconds, a tumor size decrease was already observed, demonstrating the robustness of the strategy. As an indication, a 3D reconstruction of the tumor was realized using ImageJ software. The fluorescence intensities and the volumes of tumor of zebrafish injected or not with PORBSNsmannose and submitted or not to laser irradiation were measured. Data reported in Figure $7 \mathrm{C}$ demonstrated that the excitation of PORBSNs-mannose induced approximatively a reduction of fluorescence intensity of a factor 6 (in comparison with PORBSNs-mannose only) to 7 (in comparison with laser only), and a reduction of tumor volume of a factor 4 in comparison with both conditions.

These data demonstrate the strong potential of PORBSNsmannose for in vivo TPE-PDT of tumor.

To investigate how PORBSNs-mannose induced tumor regression, we used confocal microscopy imaging of immunostained fixed injected zebrafish larvae at $6 \mathrm{dpf}$. Indeed, the fixed larvae were treated with a primary antibody specific of caspase 3 , which is expressed during apoptosis. Three dimensions (3D) stack acquisitions were performed on each larva. As shown in 3D image reconstitution (Figure 8), control larvae without tumor xenograft did not present any red or white signal with or without irradiation (Figure 8A,D). In contrast, a clear dispersion of the red cancer cells among the blue nuclei could be observed on larvae injected with MDA-MB-231 cells (Figure 8B,E). When larvae were successively injected with MDAMB-231 cells and PORBSNs-mannose and submitted to TPE, a strong disappearance of the tumor could be observed, and abundant white dots were revealed in the presence of anti-caspase 3 antibodies, thus specifying apoptotic death of cancer cells (Figure 8F).

\section{4 | DISCUSSION}

In this work, we reported small-sized PORBSNs-mannose constituted of porphyrins and anchored with mannose moieties. These nanoparticles present a high potential in biomedical applications. First, the use of BSN allows a good biocompatibility because of the high quantity of organic moieties in this hybrid nanomaterial. ${ }^{4}$ Secondly, the porphyrins organized in J aggregates inside the BSN could be excited with a pulsed laser in near-infrared wavelengths. This means that, in these nanoparticles, besides exciting by a monophotonic source of laser, porphyrins were excited with a two-photon laser with a strong efficiency. Currently, the two-photon laser excitation in the near infrared region leads to an increased penetration depth in tissues with less photodamages and with a spatiotemporal resolution suitable for small-sized tumors. ${ }^{6,34,35}$ Thirdly, the anchoring of PEG and mannose moieties at the surface of PORBSNs brings solubility, furtivity, and finally selectivity toward breast cancer cells known to overexpress mannose receptors. ${ }^{25,31}$ All together, these characteristics have suggested the biomedical potential of such PORBSNs-mannose demonstrating biocompatibility and effectiveness for cancer therapy.

The in vitro experiments we performed on human breast cancer cells in culture have confirmed that PORBSNs-mannose were safe 
(A)

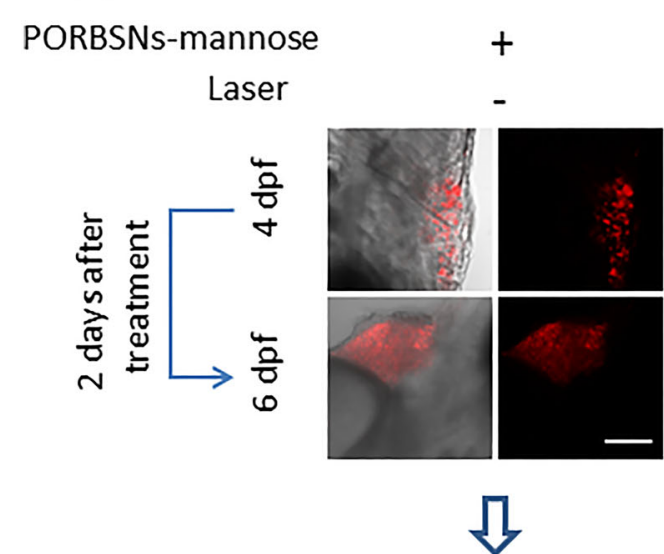

Tumor increase

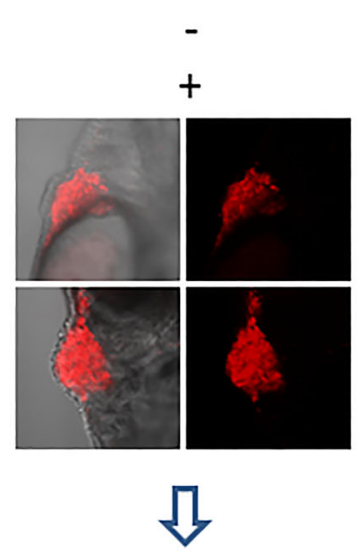

Tumor increase

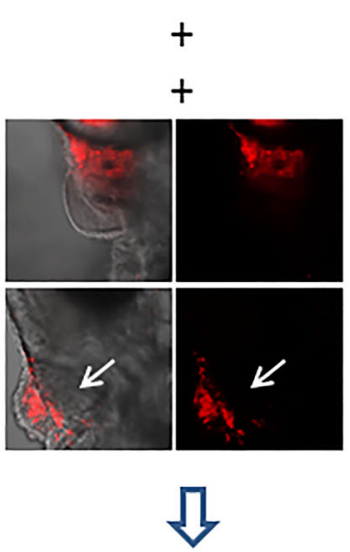

Tumor decrease

(B)

\begin{tabular}{|l|c|c|c|c|}
\hline & $\begin{array}{l}\text { Tumor size 48 h } \\
\text { after irradiation } \\
\text { or not (exp 1) }\end{array}$ & $\begin{array}{l}\text { Tumor size 48 h } \\
\text { after irradiation } \\
\text { or not (exp 2) }\end{array}$ & $\begin{array}{l}\text { Tumor size 48 h } \\
\text { after irradiation } \\
\text { or not (exp 3) }\end{array}$ & $\begin{array}{l}\text { Tumor size 48 h } \\
\text { after irradiation } \\
\text { or not (exp 4) }\end{array}$ \\
\hline Control & - & - & - & - \\
\hline Grafted tumor & $\lambda$ & $\lambda$ & $\lambda$ & $\lambda$ \\
\hline Grafted tumor+ laser & $\lambda$ & $\lambda$ & $\lambda$ & $\lambda$ \\
\hline Grafted tumor+ PORBSNs-mannose (iv) & $\lambda$ & $\lambda$ & $\lambda$ & $\lambda$ \\
\hline $\begin{array}{l}\text { Grafted tumor+ PORBSNs-mannose (iv) } \\
\text { +laser }\end{array}$ & $\searrow$ & $\searrow$ & $\searrow$ & $\searrow$ \\
\hline
\end{tabular}

(C)

\begin{tabular}{|c|c|c|c|}
\hline $\begin{array}{c}\text { Tumor measurement of } \\
\text { zebrafish }\end{array}$ & $\begin{array}{c}\text { Nolaser } \\
+ \text { PORBSNs }\end{array}$ & $\begin{array}{c}\text { Laser } \\
\text { - PORBSNs }\end{array}$ & $\begin{array}{c}\text { Laser } \\
\text { + PORBSNs }\end{array}$ \\
\hline Fluorescenceintensity (a.u.) & 10329.40 & 12164.38 & 1654.50 \\
\hline Volume $\left(\mu \mathrm{m}^{3}\right)$ & 1359.18 & 1285.02 & 324.04 \\
\hline
\end{tabular}

FIGURE 7 In vivo TPE-PDT experiments on human tumor xenografted on zebrafish. A, Confocal fluorescence microscopy of 4 and 6 days postfertilization (dpf) live larvae injected with MDA-MB-231 cells. Left panels represent the brightfield channel and right ones the Dil staining (red). All images were performed on the perivitelline space (tumor injection site) with the $20 \times$ objective. Zebrafish were injected or not with $4 \mathrm{mg} \cdot \mathrm{mL}^{-1}$ PORBSNs-mannose (intravenously) and submitted or not to two-photon irradiation. Scale bar represents $10 \mu \mathrm{m}$ for all photos. B, Summary table of the four conducted experiments. For each experiment, seven or eight larvae are injected with cancerous cells, and four are chosen on the basis of the homogeneity of the visualized tumor masses. The evolution of the size of the tumors observed is reported in the table and represented by $\nearrow$ for a tumor increase and $\searrow$ for a tumor decrease. C, Measurements of the fluorescence intensities and tumor volumes of xenografts in zebrafish embryos quantified by ImageJ software after 3D reconstruction of Z-stacks

and induced cancer cell death upon irradiation with OPE or TPE. In a second time, we developed an animal model to study the TPE-PDT efficacy of PORBSNs-mannose on human tumor. For this, zebrafish embryos were injected with MDA-MB-231 human cancer cells stained with (red) Dil staining. After 2 days, the colored tumors developed. We have demonstrated that the intravenous injection of PORBSNsmannose allowed targeting the tumor as confirmed by the reduction of the tumor size after irradiation. The tumor sizes increase in all other conditions such as laser alone or injection alone, demonstrating the efficiency of the focused irradiation of tumor area with a pulsed laser when animals were treated with targeted nanoparticles.
Finally, in this study, we decided to go further in the description of the mechanism involved in tumor reduction. Although we have demonstrated the elevation of ROS production in cancer cells, we decided to show the involvement of caspases apoptotic pathway during the TPE-PDT in zebrafish embryos bearing tumor. Our experiments described that the tumor disappearance was concomitant and colocalized with an important increase in caspase-3 level. This is consistent with what is known about the involvement of apoptotic pathways in PDT-induced cell death. ${ }^{33,36}$

More generally, the use of BSNs for cancer targeting is still at the very beginning, and we are convinced that small-sized BSNs 

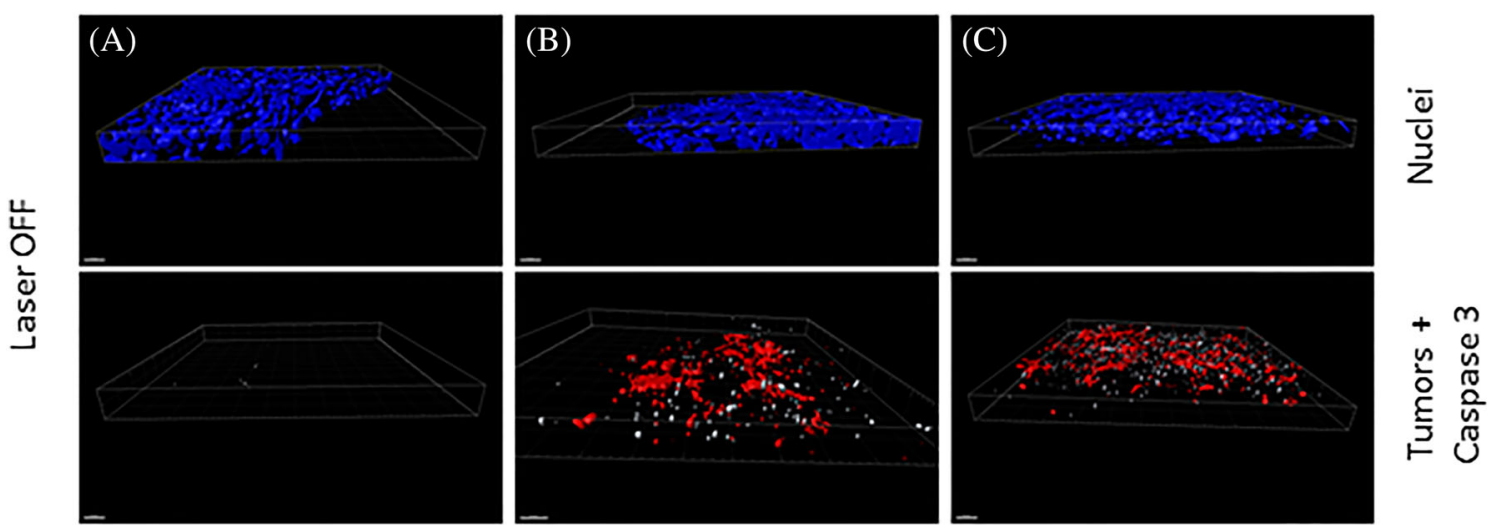

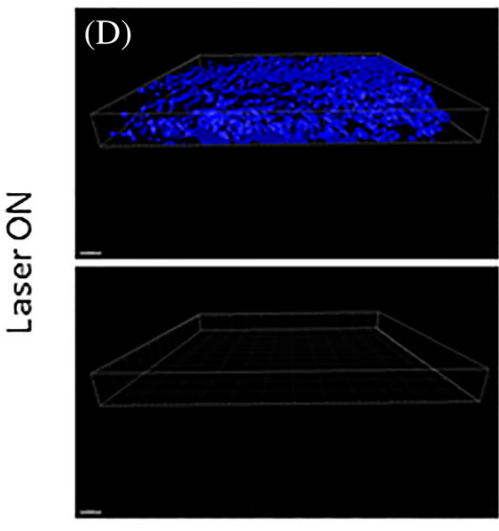

Control

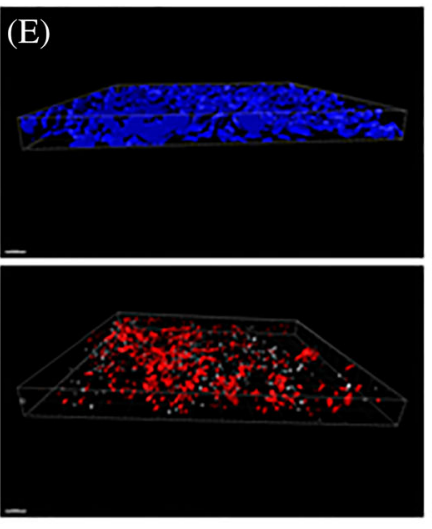

MDA-MB-231
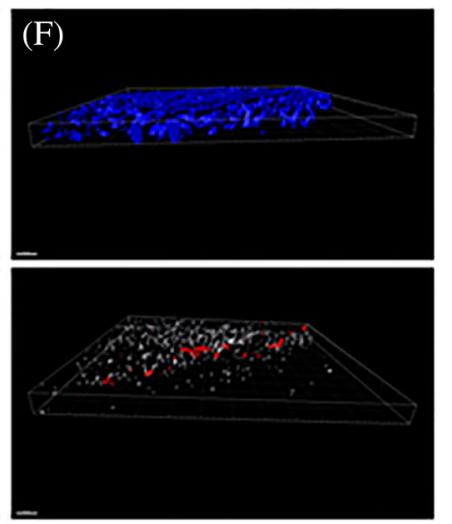

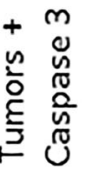

\section{PORBSNs-mannose}

MDA-MB-231 +

FIGURE 8 Xenografts apoptosis induced by TPE-PDT with PORBSNs-mannose. Three dimensions reconstitution of stacks confocal microscopy imaging of immunostained fixed (injected or no) zebrafish larvae at $6 \mathrm{dpf}$. The three dimension stacks were performed on the perivitelline space. Laser OFF (A,B,C) and laser ON (D,E,F) lines represent two different acquisitions: The nuclei on the top and the tumors with caspase 3 signal on the bottom. All images were performed with $63 \times$ Leica Apo oil, and the final reconstitution was performed using Imaris X64 8.02 software (scale bar $10 \mu \mathrm{m})$

represent a breakthrough technology in the field of TPE-PDT for cancer treatment.

\section{ACKNOWLEDGEMENTS}

S.D. thanks the Profas $\mathrm{B}^{+}$programme for a grant. ANR NanoptDPT is gratefully acknowledged. The authors thank MRI (Montpellier RIO Imaging platform) for confocal and multiphoton imaging facilities. Mireille Rossel and Nicolas Cubedo are thanked for their help for zebrafish studies. The authors thank Laure Lichon for technical assistance.

\section{CONFLICT OF INTEREST}

The authors declare that they have no conflicts of interest.

\section{AUTHORS' CONTRIBUTION}

All authors had full access to the data in the study and take responsibility for the integrity of the data and the accuracy of the data analysis. Conceptualization, S.D., C.M.J.; Methodology, S.D., C.M.J., D.A., A.L., S.D.G.; Investigation, N.B., G.H., L.R.; Formal
Analysis, S.D.G., K.B.; Resources, K.E.C., A.M., L.R.; WritingOriginal Draft, J.O.D., M.B., M.G.B.; Writing-Review \& Editing, M.G.B., N.B.; Visualization, C.N., D.D., D.A., S.D.; Supervision, J.O.D., V.S., V.C., M.W.C.M., X.C., A.M., M.G.B.; Funding Acquisition, S.D., D.A.

\section{DATA AVAILABILITY STATEMENT}

Corresponding author promises to provide the data when requested.

\section{ORCID}

Nadir Bettache (D) https://orcid.org/0000-0001-5426-7024

Magali Gary-Bobo (D) https://orcid.org/0000-0001-9641-212X

\section{REFERENCES}

1. Patra JK, Das G, Fraceto LF, et al. Nano based drug delivery systems: recent developments and future prospects. J Nanobiotechnol. 2018; 16(1).

2. Li HF, Jin H, Wan W, Wu C, Wei LX. Cancer nanomedicine: mechanisms, obstacles and strategies. Nanomedicine. 2018;13(13): 1639-1656. 
3. Mauriello-Jimenez C, Henry M, Aggad D, et al. Porphyrin- or phthalocyanine-bridged silsesquioxane nanoparticles for two-photon photodynamic therapy or photoacoustic imaging. Nanoscale. 2017; 9(43):16622-16626.

4. Croissant JG, Cattoen X, Durand J-O, Wong Chi Man M, Khashab NM. Organosilica hybrid nanomaterials with a high organic content: syntheses and applications of silsesquioxanes. Nanoscale. 2016;8(48): 19945-19972.

5. Croissant J, Maynadier M, Mongin O, et al. Enhanced two-photon fluorescence imaging and therapy of cancer cells via gold@bridged silsesquioxane nanoparticles. Small. 2015;11(3):295-299.

6. Croissant JG, Zink JI, Raehm L, Durand JO. Two-Photon-excited silica and organosilica nanoparticles for spatiotemporal cancer treatment. Adv Healthc Mater. 2018;7(7):1701248.

7. Shen Y, Shuhendler AJ, Ye D, Xu J-J, Chen H-Y. Two-photon excitation nanoparticles for photodynamic therapy. Chem Soc Rev. 2016;45(24): 6725-6741.

8. Starkey JR, Rebane AK, Drobizhev MA, et al. New two-photon activated photodynamic therapy sensitizers induce xenograft tumor regressions after near-IR laser treatment through the body of the host mouse. Clin Cancer Res. 2008;14(20):6564-6573.

9. Cao H, Wang L, Yang Y, et al. An assembled nanocomplex for improving both therapeutic efficiency and treatment depth in photodynamic therapy. Angew Chem Int Ed. 2018;57(26):7759-7763.

10. Aggad D, Jimenez CM, Dib S, et al. Gemcitabine delivery and photodynamic therapy in cancer cells via porphyrin-ethylene-based periodic mesoporous organosilica nanoparticles. Chem Nano Mat. 2018;4(1): 46-51.

11. Mauriello-Jimenez C, Knezevic NZ, Rubio YG, et al. NanodiamondPMO for two-photon PDT and drug delivery. J Mater Chem B. 2016; 4(35):5803-5808.

12. Croissant JG, Picard S, Aggad D, et al. Fluorescent periodic mesoporous organosilica nanoparticles dual-functionalized via click chemistry for two-photon photodynamic therapy in cells. J Mater Chem B. 2016;4(33):5567-5574.

13. Zhao T, Yu K, Li L, et al. Gold nanorod enhanced two-photon excitation fluorescence of photosensitizers for two-photon imaging and photodynamic therapy. ACS Appl Mater Interfaces. 2014;6(4): 2700-2708.

14. Secret E, Maynadier M, Gallud A, et al. Adv Mater. 2014;26: 7643-7648.

15. Skripka A, Valanciunaite J, Dauderis G, Poderys V, Kubiliute R, Rotomskis R. Two-photon excited quantum dots as energy donors for photosensitizer chlorin e6. J Biomed Opt. 2013;18(7): 078002.

16. Shen X, Li L, Chan ACM, Gao N, Yao SQ, Xu Q-H. Water-soluble conjugated polymers for simultaneous two-photon cell imaging and twophoton photodynamic therapy. Adv Optical Mater. 2013;1(1):92-99.

17. Jiang $C$, Zhao T, Yuan P, et al. Two-photon induced photoluminescence and singlet oxygen generation from aggregated gold nanoparticles. ACS Appl Mater Interfaces. 2013;5(11):4972-4977.

18. Fowley C, Nomikou N, McHale AP, McCaughan B, Callan JF. Extending the tissue penetration capability of conventional photosensitisers: a carbon quantum dot-protoporphyrin IX conjugate for use in twophoton excited photodynamic therapy. Chem Commun. 2013;49(79): 8934-8936.

19. Chou K-L, Won N, Kwag J, Kim S, Chen J-Y. Femto-second laser beam with a low power density achieved a two-photon photodynamic cancer therapy with quantum dots. J Mater Chem B. 2013;1(36): 4584-4592.
20. Zhao T, Shen X, Li L, et al. Gold nanorods as dual photo-sensitizing and imaging agents for two-photon photodynamic therapy. Nanoscale. 2012;4(24):7712-7719.

21. Qian J, Wang D, Cai F, Zhan Q, Wang Y, He S. Photosensitizer encapsulated organically modified silica nanoparticles for direct two-photon photodynamic therapy and In vivo functional imaging. Biomaterials. 2012;33(19):4851-4860.

22. Shen X, Li L, Wu H, Yao SQ, Xu Q-H. Photosensitizer-doped conjugated polymer nanoparticles for simultaneous two-photon imaging and two-photon photodynamic therapy in living cells. Nanoscale. 2011;3(12):5140-5146.

23. Qi Z-D, Li D-W, Jiang P, et al. Biocompatible CdSe quantum dot-based photosensitizer under two-photon excitation for photodynamic therapy. J Mater Chem. 2011;21(8):2455-2458.

24. Grimland JL, Wu C, Ramoutar RR, Brumaghim JL, McNeill J. Photosensitizer-doped conjugated polymer nanoparticles with high crosssections for one- and two-photon excitation. Nanoscale. 2011;3(4): 1451-1455.

25. Gary-Bobo M, Mir Y, Rouxel C, et al. Mannose-functionalized mesoporous silica nanoparticles for efficient two-photon photodynamic therapy of solid tumors. Angew Chem Int Ed. 2011;50(48):11425-11429.

26. Cheng $\mathrm{S}-\mathrm{H}$, Hsieh $\mathrm{C}-\mathrm{C}$, Chen $\mathrm{N}-\mathrm{T}$, et al. Well-defined mesoporous nanostructure modulates three-dimensional interface energy transfer for two-photon activated photodynamic therapy. Nano Today. 2011;6(6):552-563.

27. Howe K, Clark MD, Torroja CF, et al. The zebrafish reference genome sequence and its relationship to the human genome. Nature. 2013; 496(7446):498-503.

28. Dooley K, Zon LI. Zebrafish: a model system for the study of human disease. Curr Opin Genet Dev. 2000;10(3):252-256.

29. Manghnani PN, Wu WB, Xu SD, Hu F, Teh C, Liu B. Visualizing photodynamic therapy in transgenic zebrafish using organic nanoparticles with aggregation-induced emission. Nano-Micro Lett. 2018;10(4):61.

30. Mauriello Jimenez C, Aggad D, Croissant JG, et al. Adv Funct Mater. 2018;28.

31. Brevet D, Gary-Bobo M, Raehm L, et al. Mannose-targeted mesoporous silica nanoparticles for photodynamic therapy. Chem Commun. 2009;(12):1475-1477.

32. Warther D, Jimenez CM, Raehm L, et al. Small sized mesoporous silica nanoparticles functionalized with mannose for retinoblastoma cell imaging. RSC Adv. 2014;4(70):37171-37179.

33. Kimmel CB, Ballard WW, Kimmel SR, Ullmann B, Schilling TF. Stages of embryonic development of the zebrafish. Dev Dyn Off Pub Am Assoc Anat. 1995;203(3):253-310.

34. Zipfel WR, Williams RM, Webb WW. Nat Biotechnol. 2003;21: 1368-1376.

35. Denk W, Strickler J, Webb W. Two-photon laser scanning fluorescence microscopy. Science. 1990;248(4951):73-76.

36. Wu Y, Xing D, Luo S, Tang Y, Chen Q. Detection of caspase-3 activation in single cells by fluorescence resonance energy transfer during photodynamic therapy induced apoptosis. Cancer Lett. 2006;235(2): 239-247.

How to cite this article: Dib S, Aggad D, Mauriello Jimenez C, et al. Porphyrin-based bridged silsesquioxane nanoparticles for targeted two-photon photodynamic therapy of zebrafish xenografted with human tumor. Cancer Reports. 2019;e1186. https://doi.org/10.1002/cnr2.1186 